\title{
Mapeo de incidencia criminal en el Estado de México mediante procesamiento digital de imágenes
}

\author{
Tania Lira-Baca, Miguel Borboya Melchor, Roberto Hernández Sánchez, \\ David Tinoco Varela, Fernando Gudiño Peñaloza \\ Universidad Nacional Autónoma de México, Facultad de Estudios Superiores Cuautitlán, \\ Departamento de Ingeniería, ITSE, México \\ \{ITSE.LIRA, bm.mike07, roberto.her3130\}@gmail.com, \\ dativa19@hotmail.com, fernando.gudino@comunidad.unam.mx
}

\begin{abstract}
Resumen. Los altos índices de criminalidad presentes en diversas regiones del Estado de México son un problema social de alto impacto el cual debe ser reducido. Asociado a los grupos criminales se encuentran una serie de marcas que pasando por grafitis se confunden como arte pero que son un indicativo de la zona de influencia de los grupos criminales. La aplicación de las técnicas de inteligencia artificial para resolver problemas de impacto social ha sido uno de los principales objetivos desde su concepción. Los sistemas de procesamiento de imágenes y reconocimiento inteligente de patrones son herramientas útiles para este fin. El presente trabajo presenta un sistema de alertas compuesto por dos etapas: por una parte, se desarrolla un sistema de reconocimiento de imágenes basado en redes neuronales artificiales bajo el enfoque de MultilayerPerceptron y un esquema de entrenamiento de Backpropagation; por otra parte, se desarrolla una aplicación móvil de alertas que identifica la zona por geolocalización e indica las marcas presentes que dan una idea del índice de peligrosidad de la zona, estos índices se obtienen de la correlación entre los grafitis presentes y los reportes de grupos criminales en la zona.
\end{abstract}

Palabras clave: red neuronal Artificial, Procesamiento de Imágenes, Abatimiento de criminalidad, Aplicación móvil, Web Services, Trabajo en proceso

\section{Criminal Incidence Mapping in the State of Mexico through Digital Image Processing}

\begin{abstract}
The high crime rates present in various regions of the State of Mexico are a high impact social problem which must be reduced. Associated with the criminal groups are a series of marks that, passing through graffiti, are confused as art, but they are indicative of the zone of influence of the criminal groups. The application of artificial intelligence techniques to solve problems of social impact has been one of the main objectives since its conception. The systems of image processing and intelligent pattern recognition are useful tools for this purpose. The present work presents an alert system composed of two stages, on the one hand an image recognition system based on artificial neural networks under the Multilayer Perceptron approach and a Backpropagation training scheme. On the other hand, a mobile application of alerts is developed that identifies the zone by
\end{abstract}


geolocation and indicates the present marks that give an idea of the danger index of the zone, these indexes are obtained from the correlation between the present graffiti and the reports of criminal groups in the zone.

Keywords: artificial neural network, image processing, criminal abatement, mobile application, web services, work in progress.

\section{Introducción}

En el Estado de México existe un alto índice de inseguridad tal como lo reflejan los datos de la tasa de incidencia delictiva por entidad federativa de ocurrencia por cada cien mil habitantes reportada por el INEGI [9], en donde se demuestra un incremento delictivo latente en los últimos 6 meses, por otra parte, se observa que en los municipios con mayor incidencia delictiva, son aquellos en los cuales la proliferación de pseudoarte en forma de grafiti ha aumentado.

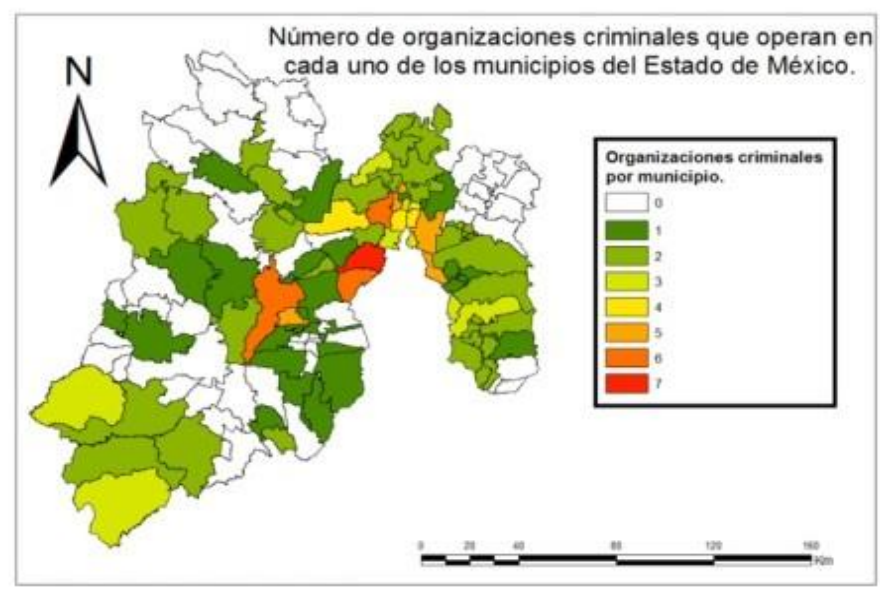

Fig. 1. Mapa de los grupos de crimen organizado por municipio en el Estado de México en 2015. Fuente: Animal Político [13].

Este tipo de arte clandestino se ha utilizado históricamente para delimitar los territorios de influencia de los diversos grupos delictivos. Con base a las diferentes marcas se podrá realizar un mapeo entre dichas marcas y los altos índices delictivos presentes en las diferentes regiones del estado y visualizar el crecimiento de las diferentes incidencias delictivas. Tal como se muestra en la Fig. 1.

El procesamiento digital de imágenes es una herramienta que nos permite detectar dentro de un área de interés en una imagen aquella información útil para la extracción de información relevante, por ejemplo, la determinación de profundidad de color nos permitirá calcular el tiempo de vida del grafiti, mientras que un sistema de mejoramiento de imágenes y localización de regiones de interés, nos permiten definir áreas en las cuales Podemos encontrar grafitis pertenecientes a diversos grupos criminales. 
Así mismo, los sistemas de clasificación basados en técnicas de inteligencia artificial, tal como una red neuronal artificial, nos permitirá agrupar en categorías a los diferentes conjuntos de marcas para crear un mapa virtual de los grupos delictivos delimitando las zonas de influencia.

Por otra parte, el auge de los dispositivos móviles actuales nos permite acercar las técnicas de inteligencia artificial aplicadas en un problema de interés general [11], que puede ser atacado por diversos frentes, en este caso mediante la prevención de delitos.

\section{Sistemas inteligentes de reconocimiento de caracteres}

Un sistema de reconocimiento de imágenes típicamente está conformado por los siguientes partes $[3,10]$.

Adquisición. Se refiere al proceso de convertir un documento a una representación apta para ser procesada por la computadora. Tal adquisición y conversión puede ser realzada por un escáner, cámara fotográfica o de video, etc. y el resultado puede variar dependiendo del proceso de digitalización usado y el método de codificación [10].

Binarización. La binarización es muy utilizada en la reproducción de imágenes, en la visión artificial y en la segmentación y reconocimiento entrópico de caracteres (OCR). Convierte la imagen recibida en una imagen binaria separando así el fondo de los objetos a analizar [10].

Normalización. Trata de ajustar la forma, tamaño y posición, esto con el objetivo de minimizar la variación entre imágenes de la misma clase [10].

Análisis de documento. Trata de analizar la estructura de un documento y enten-der la información contenida en sus componentes [10].

Segmentación. Se refiera a delimitar las regiones que nos interesan. En el caso del reconocimiento de caracteres se refiere a las líneas y caracteres individuales [10].

Extracción de características. Permite conocer las características como lo son el tamaño, perímetro, área, etc. Así como características topográficas como lo es la orientación de segmentos [10].

Reconocimiento. Convierte la imagen binaria en una representación electrónica. Misma que permite realizar operaciones de validación y análisis. Para nuestro caso se utiliza una red neuronal [10].

Prosproceso. Se refiere a mejorar el proceso de reconocimiento mediante el uso de información contextual [10].

\subsection{Procesamiento digital de imágenes}

Al conjunto de técnicas y procesos para descubrir o hacer resaltar información contenida en una imagen usando como herramienta principal una computadora se le conoce como procesamiento digital de imágenes (PDI) [12]. Los objetivos del PDI se basa en dos áreas de aplicación primordiales: El mejoramiento de la calidad de la información contenida en una imagen. El procesamiento de los datos contenidos en un escenario a través de una máquina de percepción autónoma [12]. 
Entre las aplicaciones del PDI están el reconocimiento de patrones, el cual se refiere al procesamiento de la imagen resultante del proceso de deconvolución. En esta imagen se manipulan para mejorar la lectura de la misma e identificar propiedades que pudiesen tener algún significado. La manipulación se lleva a cabo a través de tres subprocesos: resaltamiento de la imagen, reducción de ruido, segmentación y detección de bordes.

El propósito de las técnicas de realce de la imagen es mejorar la apariencia de la misma para el observador. La selección de los métodos apropiados y la elección de los parámetros adecuados dependen de la calidad de la imagen original y de la apli-cación. Entre las técnicas de realce están: Transformaciones puntuales [12]. Trans-formaciones locales [12], Transformaciones globales [12] y Transformaciones geomé-tricas.

Otro criterio de clasificación, del realce y la mejora de la imagen, tiene como base las aplicaciones que se van a efectuar. Este sistema de clasificación propone las tres categorías siguientes: Suavizado, definición y Corrección de efecto [12]. sos: resaltamiento de la imagen, reducción de ruido, segmentación y detección de bordes.

\subsection{Redes neuronales artificiales}

Una RNA (Red Neuronal Artificial) son sistemas de procesamiento de la información cuya estructura y funcionamiento están inspirados en las redes neuronales biológicas [7]. Consisten en un gran número de elementos simples de procesamiento llamadas neuronas que están organizados en capas. Cada neurona está conectada con otras neuronas mediante enlaces de comunicación, cada uno de los cuales tiene asociado un peso. Dichos pesos representan la información que será usada por la red neuronal para resolver un problema determinado.

Así, las RNA son sistemas adaptativos que aprenden de la experiencia, esto es, aprenden a llevar a cabo ciertas tareas mediante un entrenamiento con ejemplos ilustrativos. Mediante este entrenamiento o aprendizaje, las RNA crean su propia representación interna del problema.

Entre las arquitecturas de RNA más conocidas están el perceptrón multicapa MLP [7], los mapas auto organizados de Kohonen [5,7], las redes de Hopfield [7], por mencionar solo algunos de ellos.

En general cualquier sistema de RNA puede utilizar distintos paradigmas para el aprendizaje de la red, al igual que distintos tipos de entrenamiento. Tal como se observa en la Fig. 2.

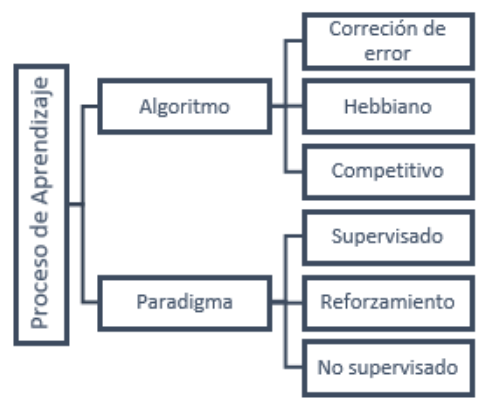

Fig. 2. Proceso de Aprendizaje en RNA. 
En este Proyecto se utiliza el paradigma de aprendizaje supervisado y el algoritmo de corrección de error BackPropagation dentro de una arquitectura de MLP [4,7].

Back Propagation. Es un método de cálculo del gradiente utilizado en algoritmos de aprendizaje supervisado utilizados para entrenar redes neuronales artificiales [7]. El método emplea un ciclo propagación (adaptación de dos fases). Una vez que se ha aplicado un patrón a la entrada de la red como estímulo, este se propaga desde la primera capa a través de las capas siguientes de la red, hasta generar una salida. La señal de salida se compara con la salida deseada y se calcula una señal de error para cada una de las salidas, Fig. 3. La importancia de este proceso consiste en que, a medida que se entrena la red, las neuronas de las capas intermedias se organizan a sí mismas de tal modo que las distintas neuronas aprenden a reconocer distintas características del es-pacio total de entrada. Después del entrenamiento, cuando se les presente un patrón arbitrario de entrada que contenga ruido o que esté incompleto, las neuronas de la capa oculta de la red responderán con una salida activa si la nueva entrada contiene un patrón que se asemeje a aquella característica que las neuronas individuales hayan aprendido a reconocer durante su entrenamiento.

\section{Sistema de mapeo de criminalidad basado en grafitis}

La creación de un Sistema de mapeo de criminalidad se desarrolla en diversas etapas, tal como se muestra en la fig. 4. En este momento el Desarrollo del Proyecto se encuentra en la construcción del Sistema de la aplicación final y en una etapa de pruebas de geolocalización. La descripción complete del sistema se da a continuación.

\subsection{Procesamiento digital de imágenes}

El Sistema se desarrolla de acuerdo a las siguientes etapas. Primeramente, se realiza el procesamiento de las señales en 5 fases: adquisición, pre- procesado, mejoramiento de las imágenes, determinación de regiones de interés y extracción de características. En la segunda etapa, se realiza la implementación del sistema de clasificación por redes neuronales artificiales y finalmente en la última tapa se implementa la solución en un servidor y se explota un servicio web mediante un dispositivo móvil, tal como se observa en la Tabla 1.

Tabla 1. Implementación de un Sistema de mapeo de grafitis. A1 es la adquisición de imágenes, A 2 es el pre procesado de las mismas, A3 es el mejoramiento de imágenes, A4 representa la selección de ROI y A5 es la extracción de características. Por otra parte, B1 representa el pre procesado de datos de entrada, B2 es el entrenamiento de la RNA y B3 es la ejecución de la misma. Finalmente, $\mathrm{C} 1$ es el desarrollo del servidor Web y C3. Es la aplicación móvil final.

\begin{tabular}{|l|l|c|c|c|c|c|}
\hline Etapa & Descripción & \multicolumn{2}{|c|}{ Componentes } & $A_{5}$ \\
\hline 1 & $\begin{array}{l}\text { Procesamiento Digital } \\
\text { de Imágenes }\end{array}$ & $A_{1}$ & $A_{2}$ & $A_{3}$ & \multicolumn{2}{|c|}{$B_{3}$} \\
\hline 2 & $\begin{array}{l}\text { Red Neuronal } \\
\text { Artificial }\end{array}$ & $B_{1}$ & \multicolumn{2}{|c|}{$B_{2}$} & \multicolumn{2}{|c|}{$C_{2}$} \\
\hline 3 & $\begin{array}{l}\text { Sistema } \\
\text { Móvil }\end{array}$ & \multicolumn{2}{|c|}{$C_{1}$} & \multicolumn{3}{|c|}{} \\
\hline
\end{tabular}




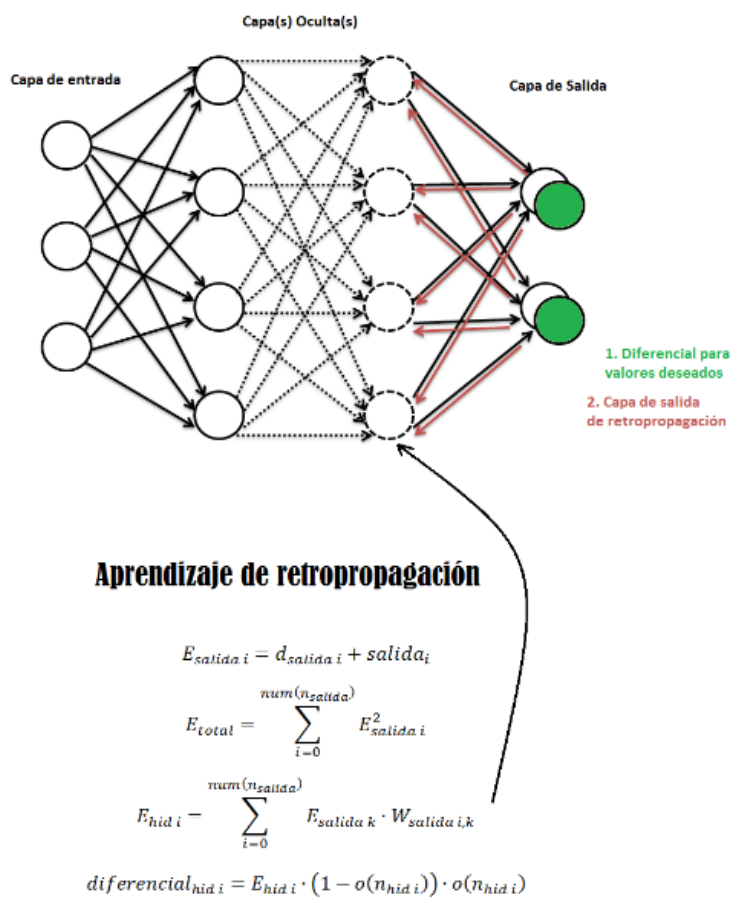

Fig. 3. Algoritmo BackPropagation.

Sistema de pre-procesamiento. En esta etapa se definieron las propiedades de captura de imagen, la resolución y profundidad de bit para las diversas tomas, así mismo se redimensionaron las imágenes para tener un estándar de calidad durante todo el proceso $[6,8]$.

Las características estandarizadas de las imágenes adquiridas se encuentran en las Tabla 2.

Tabla 2. Características de las imágenes estandarizadas para el sistema.

\begin{tabular}{|l|c|}
\hline Característica & Valor \\
\hline Ancho (pixeles) & 666 \\
\hline Alto (pixeles) & 500 \\
\hline Resolución Horizontal (ppp) & 96 \\
\hline Resolución Vertical (ppp) & 96 \\
\hline Profundidad de color (BIT) & 24 \\
\hline
\end{tabular}

Cabe aclarar que las imágenes fueron tomadas con diversos dispositivos móviles de comunicación (smartphones) de diversas marcas y con calidades ópticas variadas, tal es el caso de iPhone 6 con cámara de 8 megapíxeles, el Nokia 2 con cámara de 2 megapíxeles o Zenek León de 13 Megapíxeles. 
Sistema de mejoramiento de imágenes. Dentro de esta etapa se aplicaron diversas técnicas de realce. En primer lugar, se realizó un análisis de la composición de color de las imágenes, con el fin de determinar la profundidad de color y hacer un cálculo de la antigüedad de las diversas muestras: en grafitis antiguos el color es opaco y se visualizan intensidades bajas de la imagen, tal como se puede observar en la Fig. 4. Es importante mencionar que los índices de tonalidad dependen del fondo que se tiene, tal sea el caso de si la pared es blanca, gris, etcétera. Sin embargo, la intensidad es permanente en superficies iguales, por lo cual se puede establecer una correlación entre los colores sin importar el tipo de muro o tonalidad del mismo [12].

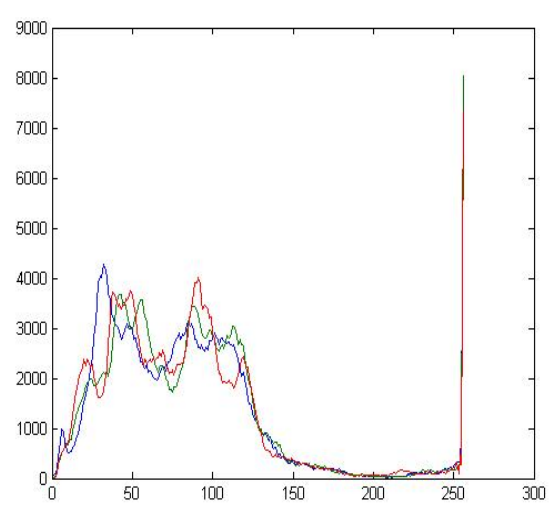

(a)

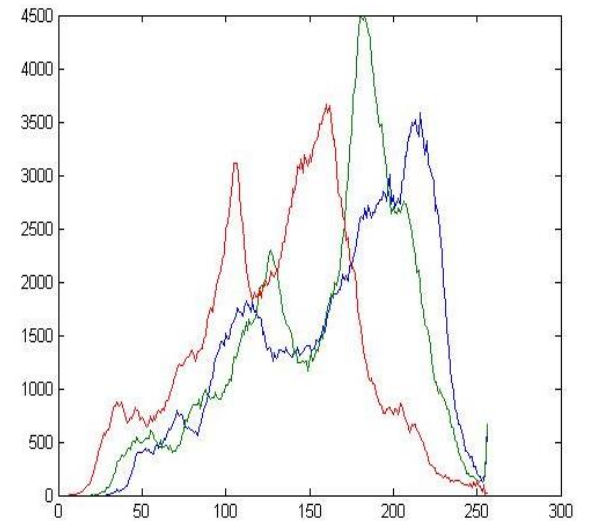

(b)

Fig. 4. Intensidades de color para dos imágenes distintas. En (a) un grafiti con más de 5 años de antigüedad. En (b) un grafiti con 1 año aproximadamente de antigüedad.

El proceso de binarización es una técnica de segmentación que se emplea cuando existe una gran diferencia entre el objeto de análisis y el fondo de la imagen, evaluando la similitud y las diferencias entre los pixeles en escalas de grises, consiste entonces, en establecer un umbral óptimo que permita la mejor separación del objeto [12].

Como paso consecuente se convirtió a las imágenes de escala RGB a escala de Grises, y se ecualizó el histograma para mejorar las diferencias y lograr así una segmentación más clara. Posteriormente se convirtió a una imagen binaria. El resultado del procedimiento se visualiza en la Fig. 5.

Una región de interés (ROI), es un área dentro de una imagen delimitada por un contorno, sobre la que se evalúa un determinado parámetro. Dentro del desarrollo del proyecto se seleccionaron de manera automática regiones con alta conectividad entre pixeles, para lo cual las imágenes binarias fueron sometidas a un proceso de erosión y dilatación.

Estas operaciones morfológicas simplifican imágenes y conservan las principales características de forma de los objetos. Un sistema de operadores de este tipo y su composición, permite que las formas subyacentes sean identificadas y reconstruidas de forma morfología óptima a partir de sus formas distorsionadas y ruidosas. Cuando los objetos de la escena sean menores que el elemento estructurante, éstos desaparecerán. 


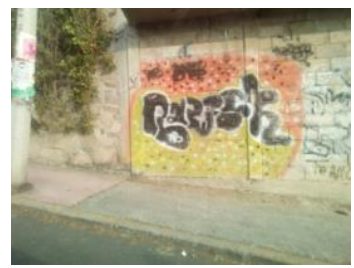

(a)

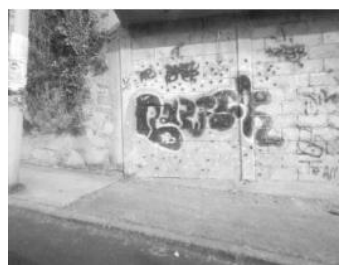

(b)

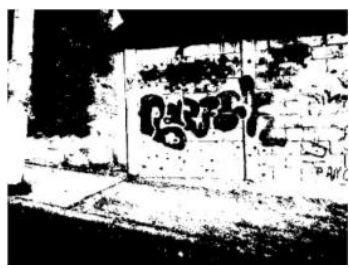

(c)

Fig. 5. Procedimiento de conversión. En (a) imagen original. E (b) imagen en escala de grises. En (c) imagen binarizada después de ecualización de histograma.

Posteriormente se aplicó un filtro de detección de contornos tipo Sobel [12] a la imagen, esta decisión se tomó dado que experimentalmente y desde un punto de vista de subjetivo fue el filtro que mejor definición de las áreas contiguas tenia.

A continuación, se marcaron regiones de al menos 30X 50 pixeles y menores a $300 X 150$ pixeles que fueran dominantes en la imagen, con esto se pretende eliminar regiones del fondo muy similares, por ejemplo, postes de luz, cortinas de negocios, o vidrios, cuyas dimensiones pueden compete con las posibles regiones de interés. De esta manera se garantiza que únicamente las áreas con probabilidad fe contener grafitis sean conservadas.

Para el etiquetado se utiliza conectividad de 8 , es decir que los 8 pixeles contiguos al de interés tuvieran un valor igual y posteriormente se aglomeraron las regiones que tuvieran un coeficiente igual en regiones más grandes hasta obtener las adecuadas. Un ejemplo lo hemos en la Fig. 6.

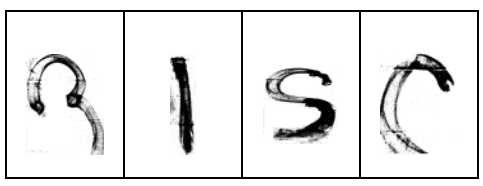

Fig. 6. Delimitación de una región de tamaño $38 X 53$ pixeles.

Una vez definida las regiones se recortaron de la imagen original, dando como resultado una región con alta probabilidad de contener un grafiti. Los resultados finales del procedimiento se observan en la Fig. 7.

Una vez obtenido los grafitis estos se guardan como matrices de dimensión 360 por 150 pixeles que son alimentados a la red neuronal en forma de vectores de datos binarios.

\subsection{Sistema de clasificación con MLP}

Para la creación del sistema de red neuronal se realizaron 3 etapas: la primera es una etapa de pre-procesamiento, para reducir la dimensionalidad de los vectores de entrada; la segunda es la etapa de entrenamiento de la red neuronal; y por último se encuentra la etapa de evaluación del sistema. Para ello se estableció que el número de clases es de 180 , correspondientes al número de muestras totales menos aquellas que se repetían determinado por un coeficiente de similaridad $[1,4,7]$. 


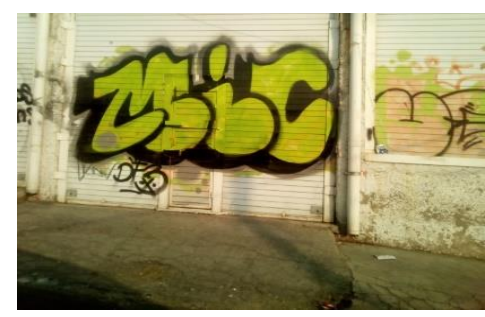

(a)

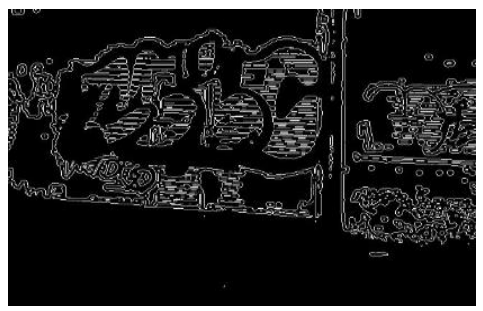

(b)

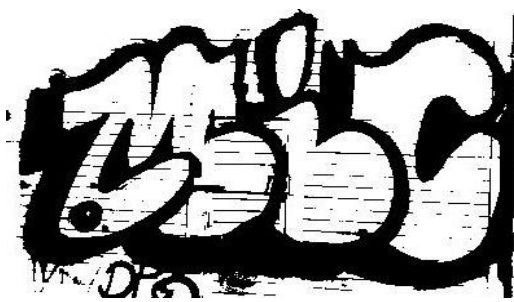

(c)

Fig. 7. Proceso para la obtención de grafitis. En (a) imagen Binaria de origen. En (b) filtro Sobel aplicado. En (c) recorte de la imagen por etiquetado de regiones.

Preprocesado de los vectores de entrada. Se generó un descriptor de características al aplicar PCA a los vectores de entrada y se aplicó un discriminante lineal $[2,8]$. El Análisis Discriminante Lineal (LDA) permite tomar dicho vector y reducir la dimensionalidad, seleccionando un número inferior de características formadas como combinación lineal de las originales, las cuales proporcionan la mayor información discriminante.

Luego de realizar LDA y aplicar una regresión lineal a las características obtenidas, para analizar el aporte de cada una de las características originales, se obtuvieron 179 funciones discriminantes, es decir, el número de clases menos uno, que separan linealmente cada una de las clases. Este análisis mostró que las características menos relevantes pueden ser omitidas y reducir los vectores originales de entrada de $360 \mathrm{X}$ 150 a vectores de $120 \times 70$.

Por lo tanto, se construyó una red neuronal con 8400 entradas, equivalente al número de componentes creados en el PCA, con 8 neuronas de salida lo que genera 256 posibles salidas siendo inhabilitadas las 76 restantes, en la capa oculta se utilizaron 5600 neuronas.

Entrenamiento de evaluación de la red neuronal. El algoritmo Backpropagation $[4,7]$ se utilizó como método de entrenamiento de la red. El primer paso en la aplicación de este método consiste en la generación aleatoria del conjunto de pesos de la red neuronal. El valor de inicialización está dado por una distribución uniforme, y cuyo rango de valores óptimos es un parámetro en estudio. Adicionalmente se consideraron los parámetros de la Tabla 3.

Para poder evaluar las características de la red obtenida se particionó el set de datos en dos subconjuntos: el subconjunto de entrenamiento y el subconjunto de evaluación. El primer subconjunto se utilizó para realizar el entrenamiento de la red, mientras que el segundo subconjunto se utilizó para evaluar la red obtenida. Se realizaron 3 
Tania Lira-Baca, Miguel Borboya Melchor, Roberto Hernández Sánchez, David Tinoco Varela, et al.

experimentos, los dos primeros con 100 muestras cada uno y 1 ultimo con los 200 ejemplos.

Tabla 3. Parámetros de configuración de la Red Neuronal bajo el algoritmo Backpropagation.

\begin{tabular}{|l|c|}
\hline Parámetro & Valor \\
\hline Cantidad de ciclos ( epochs) & 1000 \\
\hline Error máximo admisible & 0.05 \\
\hline Umbral de acierto & 0.35 \\
\hline Tasas de aprendizaje $(\alpha)$ & $\{0.01,0.05,0.1,0.25\}$ \\
\hline Taza de momento $(\beta)$ & $\{0,0.01,0.05,0.1\}$ \\
\hline
\end{tabular}

El particionamiento se realizó de manera tal que los subconjuntos resultantes sean representativos, es decir, que posean las mismas características que el conjunto original. Para la primera y segunda serie de experimentos se utilizó el mismo particionamiento del conjunto de datos. Se toman aleatoriamente el $65 \%$ de los ejemplos para entrenamiento y se dejan un $35 \%$ de ejemplos para evaluación. Finalmente, se particionó nuevamente el conjunto de datos, tomando en este caso el $80 \%$ de los ejemplos para entrenamiento.

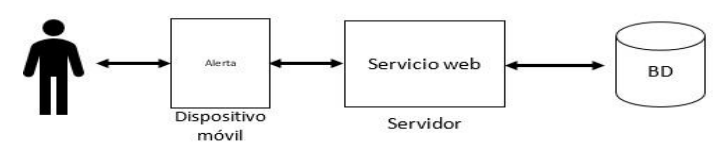

(a)

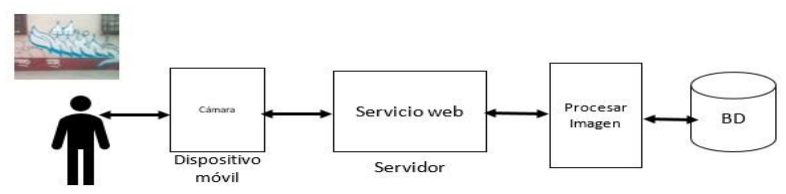

(b)

Fig. 8. Modos de operación del Sistema de usuario. En (a) en modo alerta. En (b) modo captura y actualización.

\subsection{Implementación del sistema de mapeo y geolocalización}

Actualmente esta etapa se encuentra en desarrollo, el sistema se ejecutará de dos modos, tal como se observa en la fig. 8: en el primero la idea es crear un sistema que tome la localización del dispositivo móvil y mande como referencia los grafitis que se pueden asociar a grupos delincuenciales, cabe recordar que no todos los grafitis son creados por grupos criminales, e esta manera el usuario podrá recordar aquellas imágenes que indiquen un peligro para él y tomar las precauciones debidas.

El otro modo de operación es la captura de una imagen de un grafiti y enviar la consulta al sistema, con lo cual el usuario podrá saber si este pertenece a un grupo criminal o no. Así mismo la base de datos se amplia y el sistema se mantiene actualizado [10]. 


\section{Experimentos y resultados}

Tal como se indicó anteriormente, el sistema se encuentra en la etapa final de desarrollo, por el momento únicamente se tiene los resultados del sistema de procesamiento de imágenes y del sistema de clasificación de la red neuronal.

Actualmente se cuenta con una base de datos de 500 imágenes de seis municipios correspondientes a diversas regiones del Estado de México: Atizapán, Cuautitlán, Cuautitlán Izcalli, Ecatepec, Naucalpan y Nicolas Romero. De los cuales se tienen datos de la probable creación de los grafitis en un $15 \%$ de los casos y se han identificado la participación de al menos 10 grupos delictivos, incluyendo algunos de cobertura tanto regional como nacional. Se omiten datos de los mismos por cuestiones de seguridad. En el proceso de la determinación de antigüedad con base a los datos de intensidad de color los resultados de aplicar la técnica se ven reflejados en la Tabla 4.

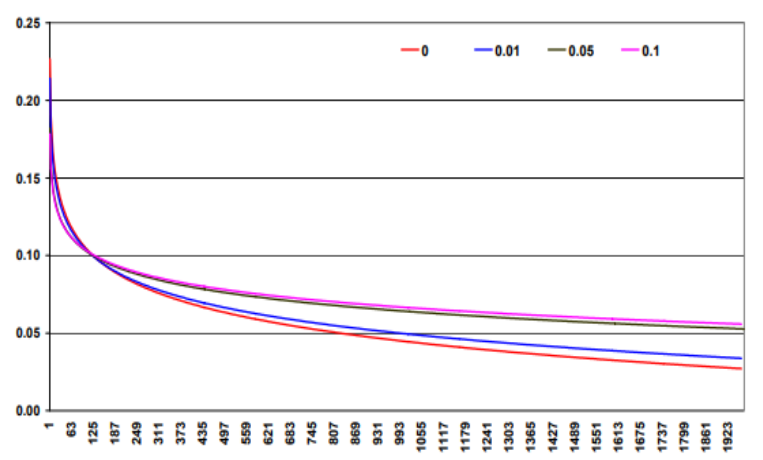

Fig. 9. Curva del error de entrenamiento para una tasa de aprendizaje $=0.1$ y diversos valores de momentos, en el eje vertical se expresa el error cuadrático medio, en el eje horizontal el tiempo de entrenamiento en segundos hasta alcanzar las 1000 épocas.

El Sistema fue alimentado con 20 imágenes de las cuales se tiene la certeza de su fecha de creación. Para ello se tomaron algunas muestras y se normalizaron dichos valores para posteriormente crear una serie de rangos de valores asociados con la edad probable de los grafitis.

Tabla 4. Resultados experimentales de la determinación de antigüedad por intensidad de color.

\begin{tabular}{|l|c|}
\hline Parámetro & Valor \\
\hline Grafitis identificados correctamente (\%) & 87.5 \\
\hline Grafitis descartados erróneamente (\%) & 12.5 \\
\hline Total de muestras & 20 \\
\hline
\end{tabular}

De la tabla 4 podemos observar que la exactitud es de tan solo el $87.5 \%$ lo cual nos indica que el sistema no es tan confiable en la clasificación. Esto se entiende por el tamaño reducido de la muestra. Por otra parte, en cuanto la capacidad de identificación de los grafitis, se procesaron para este experimento 200 muestras y los resultados se ven reflejados en la Tabla 5. 
De la Tabla 5 podemos observar que la precisión y exactitud del Sistema son altos con una baja razón de falsos positivos. Por último, los resultados del sistema de clasificación por medio de RNA se observan en la Tabla 6 y la figura 9. Este sistema se probó con las mismas 200 muestras utilizadas para el experimento anterior.

Tabla 5. Resultados de la segmentación e identificación de grafitis.

\begin{tabular}{|l|c|}
\hline Parámetro & Valor \\
\hline Promedio de grafitis por imagen & 1.2 \\
\hline Grafitis identificados y etiquetados correctamente (\%) & 97 \\
\hline Grafitis descartados erróneamente (\%) & 3 \\
\hline Regiones clasificadas erróneamente (\%) & 2 \\
\hline Regiones descartadas correctamente (\%) & 98 \\
\hline
\end{tabular}

Tabla 6. Resultados experimentales del entrenamiento y ejecución de la red neuronal.

\begin{tabular}{|l|c|}
\hline Parámetro & Valor \\
\hline Número de épocas & 1000 \\
\hline Grafitis identificados correctamente en entrenamiento (\%) & 94.32 \\
\hline Desviación estándar en entrenamiento (\%) & 0.83 \\
\hline Grafitis identificados correctamente en validación (\%) & 83.2 \\
\hline Desviación estándar en validación (\%) & 2.0 \\
\hline Grafitis identificados correctamente en promedio global (\%) & 92.1 \\
\hline Desviación estándar global (\%) & 0.8 \\
\hline
\end{tabular}

De los datos obtenidos en la Tabla 6 y la fig. 10 podemos ver un desempeño bajo en la etapa de validación. Pero un comportamiento global aceptable. El Sistema podría mejorar si se agrega una etapa de optimización, por ejemplo, mediante un Algoritmo Genético.

\section{Conclusiones}

El procesamiento de imágenes para geolocalización es, a grandes rasgos, software diseñado para recopilar información de fotografías de grafitis, con el propósito de generar delimitaciones de zonas de riesgo dentro del mapa del Estado de México. Esto logrado gracias a la codificación, en formato escala de grises y binario, de las fotos recopiladas con diversos modelos de Smartphone. Una vez que estén codificadas, con el fin de adquirir información lo más limpia posible, pasan por una etapa de filtración para eliminar datos que no sean de interés.

Utilizando un sistema de red neuronal, un proceso de aprendizaje y clasificación entra en marcha con el propósito de guardar tanto la información de origen como la obtenida del proceso dentro de una base de datos. Y para finalizar, la siguiente fase se encarga de procesar los datos para posicionar dentro del mapa las zonas de riesgo.

Tanto el software, así como cada una de las etapas que lo conforman, demuestra ser sólido en cuanto al tratado de la información base, puesto que los procesos son parte de una tecnología existente, estable y explorada a pleno, sin mencionar el gran auge en los últimos años.

Contextualizando dentro de la época, circunstancias y entorno social, es fácil orientar la idea hacia el usuario promedio, puesto que un alto porcentaje poblacional cuenta con 
Mapeo de incidencia criminal en el Estado de México mediante procesamiento digital de imágenes

algún tipo de dispositivo móvil, el cual, optimizado mediante una app, será de utilidad en cuanto a reunir la información. El beneficio al usuario es el fácil acceso a los mapas, para su uso preventivo en primera instancia, facilitando su seguridad e integridad.

Agradecimientos. Proyecto apoyado por PAPIME PE111519, y PIAPIME 4.31.05.19.

\section{Referencias}

1. Behnke, S.: Hierarchical Neural Networks for Image Interpretation. Lecture Notes in Computer Science, 2766. Springer (2003)

2. Cruz, F.C., Simas Filho, E.F., Albuquerque, M.C.S., Silva, I.C., Farias, C.T.T., Gouvêa, L.L.: Efficient feature selection for neural network based detection of flaws in steel welded joints using ultrasound testing. Ultrasonics, 73, 1-8 (2017)

3. Cubero, S., Aleixos, N., Moltó, E., Gómez-Sanchis, J., Blasco, J.: Advances in machine vision applications for automatic inspection and quality evaluation of fruits and vegetables. Food and Bioprocess Technology 4(4), 487-504 (2011)

4. Fausett, L.: Fundamentals of Neural Networks: Architectures, Algorithms, and Applications. New Jersey, USA: Prenctice-Hall (1994)

5. Fukushima, K.: Neocognitron: A self-organizing neural network for a mechanism of pattern recognition unaffected by shift in position. Biological Cybernetics 36(4), 193-202 (1980)

6. Hantson, S., Chuvieco, E., Pons, X., Domingo, C., Cea, C., Moré, G., Tejeiro, J.A. (et. al.): Cadena de pre-procesamiento estándar para las imágenes Landsat del Plan Nacional de Teledetección. Revista de Teledetección, 36, 51-61 (2011)

7. Haykin, S.S.: Neural networks and learning machines/Simon Haykin. New York: Prentice Hall (2009)

8. Hoyer \& Hyvarinen: Independent component analysis applied to feature extraction from colour and stero images. Network: Computation in Neural Systems 11(3), 191-210 (2000)

9. INEGI: Información acerca del número de eventos individuales de victimización delictiva reportados. México. http://www.beta.inegi.org.mx/temas/incidencia/, último acceso: 2019/05/11 (2017)

10. Nieto, D.: Sistema de reconocimiento de kanjis japoneses basado en procesamiento digital de imágenes aplicado a dispositivos móviles.

http://catarina.udlap.mx/u_dl_a/tales/documentos/lis/nieto_b_d/capitulo2.pdf, último acceso: 2019/05/11 (2016)

11. Richardson, L., Ruby, S.: RESTful web services, O'Reilly Media, Inc. (2008)

12. Russ, J.C.: The image processing handbook. CRC press (2016)

13. Sánchez-Valdés, V.M.: ¿Por qué aumentó la violencia en el Edomex? Animal Político. https://www.animalpolitico.com/el-blog-de-causa-en-comun/por-que-aumento-la-violenciaen-el-edomex/, último acceso: 2019/05/11 (2014) 